\title{
13. Mining, Social Change and Corporate Social Responsibility: Drawing lines in the Papua New Guinea mud
}

\section{Glenn Banks}

The Pacific Islands have been the focus of international academic and policy 'concern' in the past decade. Much of this has centred on the issue of governance, with examples such as PNG, Fiji and the Solomon Islands used to support arguments of state failures and a regional crisis of governance (see, for example, Larmour 1998; Hughes 2004). There is a tendency to see 'state failure' in these cases as an internal issue (that is, due to internal problems of governance), although this is obviously questioned by the prevalence of the problem across the region. Indeed it is surprising how little attention has been given to the ways in which external processes associated with globalisation contribute to these internal 'crises of governance'. Connected to the governance concern is a parallel policy discourse on the mismanagement of resource rents from natural resources, particularly forests and minerals. The inability to translate mineral resources into effective broader-based development and nation-building has fuelled regional resource conflicts, and necessitated regional interventions by external countries. There is evidence from elsewhere, however (see Ross 1999), that resource booms tend to undermine the very capacity for governance that economists frequently declare is needed for proper management of resource rents in the first place. Paradoxically, then, liberalisation of investment regimes and promotion of resource developments as tools for generating government revenue and economic growth are accompanied by calls for improved governance and management of resource rents despite these same rents being shown to actively undermine good governance itself.

Governance as a discourse has been touted widely by aid donors throughout the Pacific in recent years, and clearly links with broader concerns about globalisation. Receiving less attention in the region has been the parallel development of concepts of corporate governance. In contrast with broad definitions of governance along the lines of processes by which different elements in society mobilise power to influence policy and practice in the public spheres, corporate governance is concerned with more explicit themes of accountability and transparency within the private sector. In places and industries such as the PNG mining sector, the two discourses come together. Hence concerns over governance of the mining sector in PNG (in the context of the management of 
new or existing resource developments) occur alongside the formalisation of corporate governance mechanisms within the multinationals involved in the sector. Indeed one can argue that this 'corporate governance' has been implicated to a greater extent than formal 'state governance' in the development and implementation of 'good governance' within PNG. This is because within the publicly listed multinationals the links between discourse and practice are much more direct and are embedded within an institution with higher accountability and transparency requirements and standards. Thus the level of training in and implementation of 'governance' ideals for Papua New Guinean mining staff in all areas - from engineering and accountancy to the environmental fields have a greater degree of professionalism and oversight, as well as more applied utility, than in the public sector. The old adage that something lived is better learnt than something taught is of relevance here.

There is now a significant literature on communities, sustainability, corporate social responsibility and extractive industries. Much of this looks at the ways in which corporations construct notions of 'sustainability' (Cowell et al. 1999; Humphreys 2000; Cesare and Maxwell 2003) and particular communities (Hamann 2004; Jenkins 2004; Cragg and Greenbaum 2002) that reflect their own identities and agendas. Another focus of this literature is case studies of the translation of corporate notions of sustainability and responsibility into practice around specific mining or oil complexes (see Wheeler et al. 2002; Kapelus 2002; Watts 2005). One of the assumptions here is that the driver of change is only ever a globally derived discourse of sustainability, and that the local expression of the corporation (the mining operation) must always adapt to this, a point with which I take issue below.

One area of note is environmental discourse and governance, and particularly the notion of sustainability. In this paper, I am interested to explore the ways in which the corporate discourse of sustainability has impacted on the relationships between miners and communities in PNG. Using the example of Placer Dome at the Porgera mine, the paper aims to highlight how changing corporate discourses can impact on the evolution of relationships between stakeholders at the mine. In large part this occurs through the reshaping of lines, particularly the metaphorical lines of responsibility that corporations draw around themselves. The paper emphasises that discourses (such as 'sustainability') within an industry such as mining have effects - and as such they have implications for the lives and development prospects of people within affected communities (see also Hilson and Murck 2000).

The chapter opens with a discussion, albeit brief and partial, of the impacts of large-scale mining on communities with a view to identifying the processes by which these effects occur. This highlights the role of local cultural and social forces and local agency in shaping the nature of these impacts. The motivation 
and progress of the adoption of a discourse of 'sustainability' by one mining corporation (Placer Dome) and its majority-owned and -operated (by the Porgera Joint Venture, or PJV) mine at Porgera forms the basis for the second section. The link with the impacts of the mine is in terms of the shifting corporate concern with and attribution of responsibility for such impacts and effects. The third section examines the implications of this for issues of mine closure, corporate responsibility and instituting 'sustainability' around mine operations. In the conclusion, I return to the theme of the power of global discourse to reshape our understandings of and relationships to the world. Despite scepticism about the green discourse of corporations, in the Porgera case it is clear that discourse can drive new socially focused cartographic practices, and these in turn can reshape relationships and lives.

\section{Mining as the driver of change}

Large-scale mining has dramatically changed the social landscape around these mine sites in PNG. The diversity and intensity of the effects are well documented, although much of this literature is fragmentary in temporal and geographic scope. This chapter is not the forum for the overdue comprehensive review of these effects. Instead the focus is on a number of the more significant effects identified and the processes that drive these trends within the community.

Elsewhere I have identified the economic relationship between the company and the adjacent population as a central driver of many of the impacts: the substantial flows of revenue into the communities (through compensation, wages, royalties and business contracts) are implicated in sparking many of the oft-cited negative 'impacts' of mining. Here we can include in-migration (see Banks 2003) and the exaggeration of economic inequalities (Banks 2005), shifting cultural horizons and frames of reference, and the rise of all the social pathologies (alcoholism, gambling, prostitution and violence) associated with mining. Some of these effects, particularly those related to 'culture' in all its manifestations, are certainly linked to the landscape transformations and environmental destruction that accompany large-scale mining. People lose land to the bulldozer, and, as Bougainvilleans quoted by Dove et al. (1974) in the early 1970s stated, 'For us to be landless is a nightmare that no dollar in the bank can allay.' Land is so intimately tied to social relationships and identity that loss of land ruptures social as well as environmental links. In this sense the bulldozer assaults the society as completely as it does the environment. And so does the snail. Macintyre and Foale's (2004) discussion of the introduction of the Giant African snail to Lihir again highlights the cultural frames within which mine-related impacts are constructed and argued. In this case, the introduction of snails (through timber for new housing on the island that was purchased with the increased cash that landowners now have as a result of the mine) is causing havoc within the local agricultural setting. Here the issue is that local arguments frame the 
problem less as an environmental one, and more one that is concerned fundamentally with the relationship between the landowners and the company - a social rather than environmental exercise. Environmental change becomes linked back into the world of relationships - in many cases the economic relationship, framed through the lens of compensation, between communities and the mining company.

Building on the direct environmental impacts, and indeed accentuating their cultural effects, are the revenue streams with which Porgerans are supposed to be compensated for the environmental impacts. Designed (in theory at least) to be used to rebuild lives and relationships, the cash instead often erodes these further. One of the central ways in which this occurs is the in-migration associated with mine developments in PNG. In many parts of the developing world, the issue of migration and mining is concerned with the relationships between imported mine employees and local populations (e.g., Indonesia, Africa). This was also the case on Bougainville (see Imbun 1995) and to an extent at Ok Tedi (Polier 1994). At Porgera, as well as Misima and Lihir, the issue is different. Here workforces comprise workers who 'commute' without their families, and relatively small numbers of expatriate workers mean that the in-migration is driven largely through networks of kinship and relationships. The migrants are predominantly from neighbouring groups and a large proportion have utilised their kinship networks to enter and stay at Porgera. This is borne out by the figures for migration into the Special Mining Lease at Porgera (the most contested ground at Porgera, where complete strangers - unattached migrants - would have no chance of establishing a house) that show that while the 'Porgeran' population within the Special Mining Lease grew by 11 per cent in the period 1995-99, the 'epo arene' (loosely, 'visitor' or 'migrant') population grew by more than 250 per cent in the same period (Banks 2003). Importantly, the utilisation of individual kin networks by migrants to secure residence implicates Porgerans in this process, a fact that is acknowledged by community members with the caveat that they feel custom-bound to accommodate their incoming kin (see Banks 1999).

While the make-up of migrant groups and the pathways they utilise to become established might differ from other settings, the attractions are always the same: money, jobs, development and 'action'. Likewise the outcomes for the resident population tend to be the same regardless of the specific nature of the migrants. Here we can list the 'watering' down of benefits intended for landowners cash, jobs, wages, health and education services, and housing — in the form of pressure on subsistence resources (water, agricultural land, the village environment), the straining of social relationships and a general rise in feelings of insecurity due to increasing numbers of 'faces we do not know', migrants who are not part of their existing social universe. This last effect forms part of the larger sense in which landowning 'communities' themselves become more 
complex: they shift from being relatively self-contained and known (by the people in them, at least) to being much more diverse and fragmented in terms of people and agendas, and residents experience a loss of control, direction and security in their lives.

The almost legendary short-term consumption focus of Papua New Guinean mining and petroleum landowners is in part a reflection of this insecurity. But in the case of Porgera, as Alex Golub (2003) has perceptively observed, it is also in a somewhat perverse way an attempt by Porgeran Ipili to 'become more like themselves than they ever were', to exaggerate elements of their own culture to an extreme, in the same way that we can refer to the broader developments at these mine sites as a form of 'hyper-development'. It is not a lack of development as usually conceived (benefits, cash and infrastructure) but a surfeit of these that drives many of the problematic aspects of the mines (Banks 2005). It is not the tools or technology of 'development', then, that are the problem, rather it is the cultural appropriation of these technologies by the Ipili that drives the outcomes we tend to recognise as the 'pathologies' of mining.

This untangling of lines of responsibility for the various effects is important, not for the attribution of 'blame' but for the modification or redirection of trajectories of change. The case I have put above has been deliberately a caricature and a reversal of the standard narrative of mining in PNG. But it is an important check in terms of discussions about the responsibilities of mining companies in PNG and elsewhere. Put simply, to attribute responsibility for problems of alcoholism, of a decline in the effectiveness of leadership, of increasing rates of domestic violence, or the myriad other indirect effects of mining developments to the mining company is to miss the agency and cultural inflections of the Ipili (and their neighbours, it must be said) in shaping the outcomes of the mining development. This has implications when we begin to think about the extent of control of the mining company over the processes and hence possible remedies: the line of maximal extent of responsibility, in other words. Drawing these lines is never a simple task and will itself always be a point of contestation. What is particularly interesting at Porgera is the way in which one of the parties, the mining company, has redrawn its view of where the line in the mud at Porgera is in terms of its responsibilities. It is to this redrawing in the past 15 years that the chapter now turns.

\section{Entering the sustainability debate}

The evolution of interest in the discourse of sustainability by the PJV, the mining company at Porgera, makes an interesting case study of the motives, means and outcomes of corporate attachment to sustainability. From the start of the operation, the company put resources into meeting and indeed exceeding the environmental expectations of its key stakeholders, the National Government and the local community at Porgera (although in the late 1980s these groups 
would not have known they were stakeholders as the word did not have the currency it has had subsequently). Hence, after some negotiations, the extensive Environmental Impact Assessment was accepted by the State, as was the subsequent Environmental Monitoring and Management Plan. The mine began construction in 1989 and production in late 1990.

An environmental management program was established, focusing on monitoring the effects of the mine's tailings and waste on the downstream environment. The environment team worked alongside, although not closely in tandem with, a community affairs group, focused primarily on two main issues. These were day-to-day community relations with the Porgeran community, and relocation and social development, concerned primarily with helping women adjust to the new housing and social problems created within the Special Mining Lease area and, to a lesser extent, elsewhere in the Porgera Valley and, to an even lesser extent, beyond. The community affairs focus was circumscribed geographically and reactive in the sense that its major concern was with managing the day-to-day issues and conflicts that arose between the company and the community. Likewise, the environment team maintained a strong focus on the compliance monitoring of water quality along the downstream river system as it was required to by the Environmental Monitoring and Management Plan and the Department of Environment and Conservation.

The relatively cosy calm of this situation was shaken in late 1995 when a documentary on Porgera aired on SBS Television in Australia to coincide with the release by the newly established Mineral Policy Institute (MPI) of a report entitled, The Porgera File (MPI 1995). The report and the documentary were based on an Honours thesis by Phil Shearman, a geographer at the University of Tasmania, who had conducted environmental fieldwork downstream from the mine (Shearman 1995). In the ensuing media scrum, Porgera was suddenly being compared poorly with Ok Tedi, where BHP had just settled the lawsuit brought by landowners downstream of the mine for an estimated cost of $\$ 500$ million (see Kennedy 1996a, 1996b), and there were allegations that the mine tailings were killing people downstream. Initially there were said to be 133 such victims. Soon after, in March 1996, the operator and key shareholder in the PJV, Placer Dome Asia-Pacific (PDAP; itself a publicly listed, majority-owned subsidiary of Placer Dome), became embroiled in and embarrassed by a major tailings spill at the Maranduque mine in the Philippines.

Together these two events sparked the formalisation of a higher profile for environmental issues within the corporation. Driven largely by the PDAP Environment Manager at the time, PDAP became the first business unit of Placer Dome to adopt a more rigorous and transparent approach to reporting on environmental and social issues, putting out a corporate-wide first Sustainability Report in 1998, entitled Towards Sustainability, on events and progress in 1997 
(PDAP 1998). A year later, Placer Dome published its own first annual Sustainability Report (Placer Dome 1999) and this was accompanied by operation-level sustainability reports in 1999 that were effectively reviews of sustainability related issues for the previous year (see, for example, PDAP 1999). These reports have now become increasingly sophisticated and glossy annual publications, and corporate-level reporting on sustainability has also continued. This high-level corporate adoption of the sustainability discourse has not of course occurred in isolation, and broader industry trends around sustainability have been watched and participated in by Placer Dome, including the Global Mining Initiative and the Mining, Minerals and Sustainable Development process.

In the Porgera case, the response at the mine level to the MPI document (although it was never publicly acknowledged as being in any way related to the MPI report) was the commissioning of a major report by the CSIRO (CSIRO 1996) into the downstream riverine effects of the mine. Flowing from the CSIRO report (which essentially cleared the company of any involvement in deaths, but charged it with an inadequate knowledge of the downstream environment) was the establishment of the Porgera Environment Advisory Komiti (PEAK). PEAK was originally tasked with being an external advisory and reference group to 'enhance the understanding of Porgera's environmental (physical and social) issues with external stakeholders, and to assist in improving PJV's environmental performance and public accountability in these areas' (PEAK Charter). Its primary original aim was to provide an oversight function in terms of the implementation of the recommendations of the CSIRO report.

PEAK membership was originally intended to comprise a group of NGOs, PNG government departments (Mining, and Environment and Conservation), landowners and mining company representatives, along with technical advisers that each member could nominate. Due more to logistical and representational difficulties than intent, the landowners, who were to be from the middle and lower Strickland, never made it to the PEAK table. PEAK has maintained a relatively high profile on the riverine issues and, despite a turnover of personnel (some in controversial circumstances), has developed at least some credibility and been an important element in reducing external criticism of the Porgera project.

PEAK has never had a strong mandate for or presence at the mine site itself (although recent discussions within PEAK over its future might change this). Indeed it can be argued more broadly that adoption of the rhetoric of sustainability at the mine site had little influence on the structures and practices of the PJV towards the Porgeran community for at least five years. Recently though, this has changed, and two related events have led to the adoption of new approaches and structures aligned much more closely to the rhetoric and the concept of sustainability. The failure of negotiations over access to land 
within the Special Mining Lease in 2000-2001 (the Yakatabari negotiations detailed in Golub 2005) and the subsequent rethinking of the mine design and waste dump strategies had implications for the ways in which longer-term community issues were approached. Essentially, communities which it was anticipated would be relocated as part of the development of the new waste dump were not moved, and this led to some re-evaluation of the future of these communities. Directly following this process, but apparently independent of it, was the initiation of a mine closure planning process within the company. This led to the publication in December 2002 of the Porgera Mine Closure Consultation document (PJV 2002) that canvassed a range of social and economic issues in the context of the gradual wind-down and closure of the mine, scheduled for 2014.

At the same time, in 2002, a position was created to head up a Social Closure and Sustainability section, working under the environment team, but also working closely with community affairs staff. In 2003, sustainability formally entered the structure of the PJV, with the creation of a 'Sustainability Manager', who effectively dealt with environmental and corporate communication issues, and with the 'sustainable development' section. In 2004, after a major internal corporate-led review, there were significant changes to the relationship between those units dealing with community and environmental issues. A new senior management position of Sustainability Manager was created with oversight of the Environment, Community Relations and Sustainable Development departments. This structure clearly reflects broader corporate concerns with the various strands of sustainability, even if these concerns were not the overriding rationale behind the restructure.

These new structures of engagement are clearly couched within the rhetoric of sustainability. From their limited origins as a response to external criticism of the handling of environmental issues, evolving corporate notions of sustainability have become entrenched in the rhetoric, structures and practices of the PJV. Shifts have clearly occurred in the discourse of the corporation and the company that it manages, and the internal structure of the company has been reshaped to reflect this. The focus on mine closure issues has given the concept of sustainability 'teeth' or traction within the company and in its dealings with the community.

In large part this has been reactive and in response to corporate problems and issues, but it has also been driven by key 'change individuals' within the corporate management, and has occurred in the context of the rapidly developing global discourse on sustainability (Cowell et al. 1999; Hilson and Murck 2000; MMSD 2002). It should also be noted that while the reactive nature of mines to community concerns is a typical marker of an early operation, the more mature operation (and more established relationships) facilitates planning within a less reactive 'sustainability' framework. In other words, the mine is more proactive 
in terms of its social and environmental planning (and hence better fits notions of best practice) in part at least because it is not as preoccupied with as many day-to-day issues and crises. In the final section of the paper, the effects of this corporate realignment towards sustainability in terms of notions of boundaries and responsibilities are outlined.

\section{Drawing lines}

Mining operations are constantly drawing lines of all kinds. Perhaps the most influential are the precisely surveyed lines that define the mining leases. These can be viewed as expansive at Porgera, with a number of new additional leases being mapped out in the past decade as the waste dumps from the mine have extended in different directions. These lines are critical, as they define a line in terms of the knowledge that companies have of the communities on either side (with generally much better knowledge of the individuals and relationships of those inside), and mark an abrupt economic schism between ground eligible for royalties and other economic benefits and land which is not. Rather than existing as the sole cadastral markers on the landscape, though, these lease boundaries intersect with the genealogically grounded lines of landownership around the mine sites (for in-depth anthropological accounts of the basis for these genealogical lines at Porgera see the PhD dissertations of Jacka (2003) and Golub (2005). Biersack (1999) and Jackson and Banks (2002) provide accessible introductions, while Jorgenson (1997) provides a more general statement on the issue). Many of these socially derived boundaries are natural features (ridges, rivers, etc.), in contrast with the systematically and precisely surveyed straight lines of mining leases.

A third set of lines, and the ones of most interest in the current context, are those of corporate responsibility: what is the extent, geographically and in terms of sectors and issues, of corporate responsibility in social terms at Porgera? Where geographically and socially do the boundaries of corporate responsibility extend? This is really a question of which communities the mining companies are responsible for, and to (and often these are two different groups). At Porgera at least this question is closely linked with the previous section. In the initial stages of the mine development, the mining company's most immediate concern was the relationship with the landowners of the Special Mining Lease area, a tightly circumscribed geographic and social group (the role of migrants within this geographic area was problematic and the source of much early concern from the company, see Robinson (1991, 1994)). Other lease landowners were certainly important, and those along the Hides power line became critical for a short time until their leases were negotiated, but the Special Mining Lease landowners had assumed a position of dominance on the mine's corporate radar, as indeed they had on the local, and the national, horizon. 
Even within these leases, though, the areas of corporate responsibility were tightly prescribed and certainly not all-embracing. Two examples should serve to illustrate the point. First, the company assumed no responsibility for the maintenance of the new, permanent-material houses that had been constructed for relocated families within and around the mining leases. This was clearly stated in the Relocation Agreement signed between the company and the Special Mining Lease community in 1988, and has been tightly adhered to in the face of increasing demands for assistance as the houses have aged and deteriorated in the past 15 years. Second, the company never assumed any role in terms of the division or use of monies within landowning groups within the Special Mining Lease or the other leases. Thus, once the agents of the extended family group who were the recognised 'landowners' of a particular parcel of land eligible for compensation had been identified, and once a list of recipients had been submitted by the group to the lands office of the company, the cash (in the overwhelming majority of cases, it was cash) was simply handed over to the listed beneficiaries. There were few attempts made to either ensure the cash was appropriately distributed (according to notions of 'tradition' or 'equity') among all the eligible recipients, or to intervene in terms of the uses to which the cash was put. This was not an oversight, mischievous or deliberate, by the company - any such attempt in either area would have been outside the legal scope of the company, would have been strenuously resisted by landowners and would have attracted allegations of paternalism by Porgerans and observers.

Subsequently a number of factors have extended this relatively small geographic horizon of corporate interest and responsibility. The first, referred to above, has been the increase in the number and extent of leases associated with the mine. While this essentially incorporated more people into the immediate group of interest to the mining company, there have been changes in the nature of the relationship between the company and these communities, which are discussed below. A second actor in the extension of the boundaries of corporate responsibility at Porgera, and subsequently elsewhere in PNG, was the introduction of the Infrastructure Tax Credit Scheme (ITCS or often just TCS) in 1992. Under the TCS, the company could spend a small proportion of its annual gross revenue — between 0.75 per cent and 1.25 per cent - on community infrastructure within the province in return for a credit against its tax assessment from the National Government. This scheme had its origins in management concerns at Porgera with the return of tax revenue from the mine to the province. Given the exposure of the mine to disruption along the extended road linkage through Enga Province, the TCS was seen as a way of spreading the corporation's responsibilities (in a limited way) beyond just the Porgera Valley. The boundary of the company's attention, albeit a partial view with at least one eye kept on the bottom-line, extended dramatically with the TCS. 
A third set of influences in reshaping the boundaries of corporate social responsibility have been events such as media controversy about downstream pollution in the mid-1990s. Where the direct financial interests of the company or its image have been threatened or compromised by actors outside its own notion of its existing boundaries of responsibility, then the boundaries have widened. Hence, in the wake of the downstream riverine pollution controversy, much more attention was paid to the broadly defined developmental needs of the communities along the Laigaip and Strickland River systems, and these villages received water tanks, bridges, compensation and health patrol visits (see PEAK web site for details of some of these). Likewise, the disintegration of public order in Southern Highlands Province in 2002, along with the felling of numerous pylons along the transmission line from the Hides gas plant to the mine, brought an intensive period of company interventions in terms of support for the restoration of law and order and much broader-based development efforts within a community that had previously been marginal to the mine. The deterioration of law and order and the physical road along the Highlands Highway also saw the commitment of much greater funds by the PJV and other resource companies to this area, some of which took the form of an additional TCS.

Finally, and most significantly in terms of the current argument, the refinement and increasing traction of notions of sustainability within the corporation have significantly reshaped the geographic and metaphoric boundaries of corporate responsibility at Porgera. The scope of 'community' at Porgera has been broadened by the corporate focus on sustainability. This was shown by the production of a Porgera Mine Closure Consultation Document at the end of 2002, in which it was clear that while the Special Mining Lease communities presented one geographic group in terms of mine closure, the social and economic issues faced ran significantly wider - into, for example, areas of local governance and economic development across the district and beyond (PJV 2002). The Closure Consultation Document was an attempt to map out those areas and those parties with responsibility for addressing different community issues, making the point that the mining company was rarely the sole party with responsibilities or influence in the area (and the other parties included various arms of the State and the community itself): indeed, in many areas the potential contribution of the company beyond mine closure was limited. Partnerships with NGOs were seen as a potential way of extending influence beyond this point, although few NGOs were tempted by the prospect of multinational mining houses as partners (though at least one major long-term NGO partner has been secured at Porgera).

In terms of social responsibility, there are signs that the PJV has sought to extend its influence over some of the more destructive community processes, albeit in limited ways. One example is the writing into new relocation and compensation agreements of alternatives to permanent-material houses and cash payouts. Two 
such schemes included assistance with real estate investments, and the use of trust funds to ensure the value of relocation packages were maintained until at least the end of the mine life. The first of these has been popular among the latest round of relocated parties, although a number of 'cultural influences' have also started to impact on the success of these schemes.

Interestingly, the effect of sustainability as a discourse on such boundaries is now the subject of increasing institutional interest among multinationals. An industry-led Global Reporting Initiative recently brought out a report on the issue of where the boundaries of responsibility lie when it comes to the reporting of progress towards sustainability (GRI 2005). In this report, the issue of control and influence is central: that is, over what subsidiaries does the corporation extend control and influence in terms of reporting its compliance with sustainability targets and guidelines? Much the same debate occurs at Porgera over the responsibility of the company for 'leaving behind a better future'. The key emphasis from the company perspective is to identify those areas and issues where they are able to influence or control processes and events in a way that can translate into tangible positive outcomes. The trust funds and NGO partnerships mentioned above are viewed in this light. Obviously, such long-term planning is far removed from the reactive nature of early PJV community affairs at Porgera. To be clear, then, the lines of corporate concern and responsibility at Porgera have been continually redrawn in an expansive way by the corporation and other parties with influence over it, and have recently been heavily influenced by the discourse of sustainability, a key element of current global corporate rhetoric and governance.

\section{Conclusions}

The increasing emphasis on notions of sustainability, especially in the context of mine closure, and social responsibility at the global level has led to discussion within corporations, national governments and international institutions about the limits of responsibility for, and their ability to mitigate, negative social effects within communities. This has occurred at the same time as transparency and social responsibility have become central to notions of corporate governance among multinationals in developing countries. The boundaries of corporate social responsibility and the limits for reporting of progress towards sustainability are increasingly being institutionalised through global regimes and standards. In this paper, some of these limits have been outlined in the context of the Porgera mine. External factors, global trends and key personnel have all been important in reshaping boundaries of corporate influence and responsibility at Porgera in the past decade. There is a tendency to see global capital as static once it becomes established at particular locations. Instead, as we have seen, there is a constant dialectic between local and global discourses that the company must traverse and negotiate. And there is certainly not a unidirectional, 
global-to-local set of processes operating: events at one or two sites have had a profound influence on the higher level discourse within the corporation and this in turn feeds back to local operations.

The basic tension between drawing a line at the mine gate and behaving responsibly within it with no interest or involvement in the outside community except as it impinges on the mine operation, and becoming engaged with the myriad and complex social processes that occur within the community, is one that is constantly being negotiated by corporations in development contexts. Leaning too far one way can attract charges of corporate imperialism (or at least paternalism), while in the other direction lies irresponsibility, danger and immorality (companies that do not know about human rights violations within their sphere of influence would certainly deserve this label).

All lines in PNG are drawn in mud - the murky (in the sense of ambiguous and/or flexible) rules of community inclusion and exclusion, occasionally shifting (and sometimes less than obvious) mining lease boundaries and gradually expanding and encompassing responsibilities accepted by the mining company at Porgera. Initiated in part in response to the attacks on its environmental record, the discourse of sustainability at the corporate level has fed back into the creation of new structures and policies within the company. These map out new, expansive boundaries of social responsibility at Porgera. Despite the fact that it occurs within a discursive world dominated by global sustainability concerns, the current corporate cadastral trend at the Porgera mine site is still a largely pragmatic one, targeting those areas where some degree of control over process is possible and results are tangible. This makes for safer public relations and sustainability reporting, and hence is too easily labelled as a more sophisticated form of corporate green-washing, but it might also represent the real limits of corporate power in these highly dynamic and complex social environments.

\section{References}

Ballard, C. and G. Banks. 2003. 'Resource Wars: Mining and Anthropology.' Annual Review of Anthropology, 32. pp. 287-313.

Banks, G. 1999. 'Gardens and Wantoks.' In C. Filer (ed.), Dilemmas of Development: The Social and Economic Impact of the Porgera gold mine 1989-1994, Canberra and Port Moresby: Asia-Pacific Press (Pacific Policy Paper, 34), Resource Management in Asia Pacific Project, and National Research Institute (Special Publication, 24). pp. 160-90.

Banks, G. 2003. "“Faces we do not know": Mining and migration in the Melanesian context.' Unpublished paper presented at the Mining Frontiers: Social conflicts, property relations and cultural change in emerging boom regions workshop, Halle/Saale, Germany, June 18, 2003. 
Banks, G. 2005. 'Globalization, poverty, and hyperdevelopment in Papua New Guinea's mining sector.' Focaal, European Journal of Anthropology, 46. pp. $128-43$.

Biersack, A. 1999. 'Porgera - Whence and Whither?' In C. Filer (ed.), Dilemmas of Development: The Social and Economic Impact of the Porgera Gold Mine, 1989-1994, Canberra and Port Moresby:Asia Pacific Press and National Research Institute. pp. 260-79.

Cesare, P. and P. Maxwell. 2003. 'Mine closure legislation in Indonesia: The role of mineral industry involvement.' Natural Resources Forum, 27. pp. $42-52$.

CSIRO. 1996. Review of Riverine Impacts: Porgera Joint Venture. Canberra: CSIRO Environmental Projects Office.

Cowell, S., W. Wehrmeyer, P. Argust and G. Robertson. 1999. 'Sustainability and the primary extraction industries: Theories and practice.' Resources Policy, 25. pp. 277-86.

Cragg, W. and A. Greenbaum. 2002. 'Reasoning about responsibilities: Mining company managers on what stakeholders are owed.' Journal of Business Ethics, 39. pp. 319-35.

Dove, J., T. Miriung and M. Togolo. 1974. 'Mining bitterness.' In P. Sack (ed.), Problem of Choice: Land in Papua New Guinea's Future, Canberra and Port Moresby: ANU Press and Robert Brown and Associates. pp. 181-9.

Filer, C. 1990. 'The Bougainville rebellion, the mining industry and the process of social disintegration in Papua New Guinea.' Canberra Anthropology, 13 (1). pp. 1-39.

Global Reporting Initiative. 2005. GRI Boundary Protocol. GRI. (Available online at http://www.globalreporting.org/guidelines/protocols/boundaries.asp

Golub, Alex. 2003. 'Migration, gold-mining and reconfigurations of kinship and ethnic relations in highlands Papua New Guinea. Cultural authenticity, novelty and cultural change.' Unpublished paper presented at the Mining Frontiers workshop, Max Planck Institute for Social Anthropology, Halle, Germany, June 18, 2003.

Golub, A. 2005. 'Making the Ipili feasible: Imagining local and global actors at the Porgera gold mine, Enga Province, Papua New Guinea.' Unpublished PhD dissertation, Department of Anthropology, University of Chicago.

Hamann, R. 2004. 'Corporate social responsibility, partnerships and institutional change: The case of mining companies in South Africa.' Natural Resources Forum, 28. pp. 278-90. 
Hilson, G. and B. Murck. 2000. 'Sustainable development in the mining industry: Clarifying the corporate perspective.' Resources Policy, 26. pp. 227-38.

Hughes, H. 2004. 'Can Papua New Guinea come back from the brink?' Issue Analysis No. 49. Sydney: The Centre for Independent Studies. (Available online at http://www.cis.org.au/)

Humphreys, D. 1999. 'A business perspective on community relations in mining.' Resources Policy, 26. pp. 127-31.

Imbun B. Y. 1995. 'Enga social life and identity in a Papua New Guinea mining town.' Oceania, 66. pp. 51-61.

Jacka, J. 2003. 'God, gold and the ground: Place-based political ecology in the New Guinea borderlands.' Unpublished PhD dissertation, Department of Anthropology, University of Oregon.

Jackson, R. and G. Banks. 2002. In Search of the Serpent's Skin: The History of the Porgera Gold Project. Port Moresby: Placer Niugini Ltd.

Jorgenson, D. 1997. 'Who and what is a landowner? Mythology and marking the ground in a Papua New Guinea mining project.' Anthropological Forum, 7 (4). pp. 599-627.

Jenkins, H. 2004. 'Corporate social responsibility and the mining industry: Conflicts and constructs.' Corporate Social Responsibility and Environmental Management, 11. pp. 23-34.

Kapelus, P. 2002. 'Mining, corporate social responsibility and "the community": The case of Rio Tinto, Richards Bay and the Mbonambi.' Journal of Business Ethics, 39. pp. 275-96.

Kennedy, D. 1996a. 'Ok Tedi all over again: Placer and the Porgera Gold Mine.' Multinational Monitor (March). pp. 22-4.

Kennedy, D. 1996b. 'Porgera: Arsenic and Gold.' Mining Monitor, 1 (2). pp. 7-8. Larmour, P. (ed.) 1998. 'Governance and reform in the South Pacific.' National Centre for Development Studies, Pacific Policy Paper 23. Canberra: ANU.

Macintyre, M. and S. Foale. 2004. 'Global Imperatives and local desires: Competing economic and environmental interests in Melanesian communities.' In V. Lockwood (ed.), Globalization and Culture Change in the Pacific Islands, Upper Saddle River, New Jersey: Pearson Prentice Hall. pp. 149-64.

Mineral Policy Institute. 1995. The Porgera File: Adding to Australia's Legacy of Destruction. Sydney: Mineral Policy Institute.

Mining, Minerals and Sustainable Development Project. 2002. Breaking New Ground: The Report of the Mining, Minerals and Sustainable Development Project. London: Earthscan. 
Placer Dome Asia Pacific. 1998. Towards Sustainability. Sydney: Placer Dome Asia Pacific.

Placer Dome Asia Pacific. 1999. Porgera Mine: 1998 Sustainability Report. Sydney: Placer Dome Asia Pacific.

Placer Dome Incorporated. 1999. Sustainability Report. Vancouver: PDI.

Polier N. 1994. 'A view from the "cyanide room": Politics and culture in a mining town in Papua New Guinea.' Identities, 1. pp. 63-84.

Porgera Joint Venture. 2002. Porgera Mine Closure Consultation Document. Porgera: PJV.

Robinson, F. 1991. 'Anthropology and the Porgera gold mine.' Paper presented at New Perspectives on the Papua New Guinea Highlands: An Interdisciplinary Conference on the Duna, Huli, and Ipili Peoples, RSPAS, ANU, Canberra, August 16-18.

Robinson, F. 1994. 'Squatters and outsiders.' Paper presented at Second Business Development and Community Affairs Conference, Port Moresby, PNG Chamber of Mining and Petroleum, March 15.

Ross, M. 1999. 'The political economy of the resource curse.' World Politics, 51 (2). pp. 297-322.

Shearman, P. 1995. 'The Environmental and Social Impact of the Porgera Gold Mine on the Strickland River System.' Unpublished BSc. (Hons) thesis, Department of Geography and Environmental Studies, University of Tasmania, Hobart.

Shearman, P. 2001. 'Giving away another river: An analysis of the impacts of the Porgera Mine on the Strickland River system.' In B. Imbun and P. A. McGavin (eds), Mining in Papua New Guinea: Analysis \& Policy Implications, Waigani, N.C.D.: University of Papua New Guinea Press. pp. 173-90.

Watts, M. 2005. 'Righteous oil? Human rights, the oil complex and corporate social responsibility.' Annual Review of Environment and Resources, 30. pp. 373-407.

Wheeler, D., H. Fabig and R. Boele. 2002. 'Paradoxes and dilemmas for stakeholder responsive firms in the extractive sector: Lessons from the case of Shell and the Ogoni.' Journal of Business Ethics, 39. pp. 297-318. 